\title{
Modelling Antarctic krill circumpolar spawning habitat quality to identify regions with potential to support high larval production
}

\section{David B. Green ${ }^{1}$, Sophie Bestley, ${ }^{1,2}$, Stuart P. Corney ${ }^{1}$, Rowan Trebilco ${ }^{2,3}$, Patrick Lehodey $^{4,5}$, and Mark A. Hindell ${ }^{1}$}

${ }^{1}$ Institute for Marine and Antarctic Studies, University of Tasmania, Australia

${ }^{2}$ CSIRO Oceans \& Atmosphere, Hobart, Tasmania, Australia

${ }^{3}$ Centre for Marine Socioecology, University of Tasmania, Australia

${ }^{4}$ Collecte Localisation Satellites, Ramonville St Agne, France

${ }^{5}$ Oceanic Fisheries Programme, Pacific Community, Noumea, New Caledonia

Corresponding author: David Green (david.green@utas.edu.au)

\section{Key Points:}

- Mechanistic model for Antarctic krill spawning habitat uses thermal and food constraints on egg production, and predation on egg survival

- Optimizing from regional data we generate circumpolar predictions to show half of quality spawning habitat is in the southwest Atlantic

- Spatial management units for the krill fishery do not all represent optimal spawning habitat, suggesting some areas rely on recruit import 


\section{Abstract}

Antarctic krill (krill) are important within Southern Ocean ecosystems and support an expanding fishery. Towards understanding krill's response to environmental change, it is necessary to identify regions that support high krill larval production (spawning habitat). We develop a mechanistic model combining thermal and food requirements for krill egg production, with predation pressure post-spawning, to predict regions of high-quality spawning habitat. We optimise our model regionally and generate circumpolar predictions of spawning habitat quality. Our results indicate the southwest Atlantic accounts for almost half of all predicted high-quality spawning habitat. Small-scale management units (SSMUs) around the Antarctic Peninsula had high coverage of high-quality spawning habitat. In contrast, the remaining SSMUs (except around South Georgia) were poorly covered, suggestive of population sinks reliant on input from external sources upstream. This implies strong potential for downstream impacts of fishing in key spawning areas, with implications for management of SSMUs and the krill fishery.

\section{Plain Language Summary}

Antarctic krill (krill) are a key prey item for many Southern Ocean marine predators and also support an expanding commercial fishery. However, there is a need to identify areas of the Southern Ocean that are best for both the production of eggs, and subsequent survival until free swimming larvae. We create a model for spawning habitat which considers the temperature and food conditions that adult female krill need to successfully produce eggs, as well as the density of predators feeding on spawned eggs. We optimize our model using existing regional-scale data of krill eggs and larvae and use this to predict where good spawning habitat may exist around the whole Southern Ocean. Our model found that nearly half of the best spawning habitat occurs in the southwest Atlantic. Within this area, small-scale krill fishing management areas around the Antarctic Peninsula contain good quality spawning habitat. Krill fished here are likely to be locally produced. But, other small-scale management areas contain little good quality spawning habitat (except around South Georgia) and probably rely on krill being imported by ocean currents. This is important for understanding how fishing may impact both local ecosystems and those that are downstream.

This article is protected by copyright. All rights reserved. 


\section{Introduction}

Antarctic krill (Euphausia superba; hereafter krill) are an important component in the Southern Ocean ecosystem and play a key role in energy flow [e.g. Ballerini et al., 2014] and nutrient cycling [Ratnarajah and Andrew, 2016] as well as supporting the Southern Oceans' largest and expanding fishery [Nicol et al., 2012]. However, krill's stenothermal nature makes them vulnerable to climate-induced biophysical change [e.g. Atkinson et al., 2019; Veytia et al., 2020]. Managing the effects of such change requires understanding the ecological mechanisms that underpin suitable krill habitat.

Krill have a highly heterogenous and changing circumpolar distribution [Marr, 1962; Yang et al., 2020] with biomass in much of their range apparently derived through advection [Fach et al., 2006; Mori et al., 2019; Thorpe et al., 2007], often from localised spawning along the Antarctic shelf slope [Conroy et al., 2020]. These source-sink dynamics suggest that local variability in spawning underpins regional-scale fluctuations in recruitment [Siegel et al., 2003], and that the population ultimately depends on habitat conditions within a fraction of its range [MelbourneThomas et al., 2016; Trebilco et al., 2019]. Yet, while much work has focused on assessing habitat quality for spawned egg survival until recruitment [Hofmann and Hüsrevoğlu, 2003; Piñones and Fedorov, 2016; Thorpe et al., 2019], or growth and survival of post-larval, first-year and adult krill, there has been comparatively little focus on similar characterisations of habitat likely to support high larval production (defined here as egg production pre-spawning and survival until the calyptopis stage).

Biophysical conditions can constrain larval production through both pre-spawning egg development and post-spawning survival, particularly as reproduction in krill is strongly dependent on temperature and food availability [Constable and Kawaguchi, 2018; Murphy et al., 2017; Piñones and Fedorov, 2016]. In adult krill, metabolic costs rise steeply as temperatures exceed $3^{\circ} \mathrm{C}$ [Atkinson et al., 2006], reducing available energy for investment in growth and reproduction. In cooler waters where metabolic costs are lower, years of above-average phytoplankton biomass (food) are associated with high larval densities [Marrari et al., 2008] and good recruitment the following year [Conroy et al., 2020; Marrari et al., 2008]. However, strong spawning output (eggs) does not necessarily translate into high larval production [Tarling et al., 2007]. Even under conditions suitable for successful egg production, spawned eggs and young larvae are vulnerable to predation pressure from micronekton [Tarling et al., 2007], particularly myctophid fish [Saunders et al., 2019]. Thus, high micronekton densities may lead to lower survival of krill eggs

This article is protected by copyright. All rights reserved. 
and larvae. High-quality realised spawning habitat for larval production would therefore combine optimal conditions both leading up to and immediately following spawning.

We present a mechanistic approach for estimating the potential habitat quality for larval production (hereafter spawning habitat quality) based on the biophysical requirements stated above. To do this we parameterise deterministic suitability functions of temperature, primary production and micronekton density, transforming these three variables into suitability scores; the product of which gives an overall index of habitat quality. We estimate model parameters through a quantitative optimisation procedure using an index of spawning habitat derived from observations around the Antarctic Peninsula (AP). We then scale-up our parameterised model beyond regional observations to explore circumpolar, seasonal and interannual patterns in predicted spawning habitat quality. Finally, we map our model output onto spatial management regions defined by the Commission for the Conservation of Antarctic Marine Living Resources (CCAMLR) to consider representativeness of optimal spawning habitat. For this, we consider broader statistical subareas together with small-scale management units (SSMUs) aimed at reducing ecosystem impacts of the fishery by spatially distributing the annual catch limit [Hill et al., 2016].

\section{Methods}

\subsection{Deriving spawning habitat quality from observations}

The most comprehensive data available on spawning habitat are in the southwest Atlantic, with regular collection of eggs and larvae since 1976 [Perry et al., 2019]. We used these data to create a regional composite map of egg, nauplii and calyptope densities encompassing the AP, Scotia Sea and South Georgia (SG; 25-70W, 50-68S; Fig. S4.).

We collated late summer (Jan-May) densities of eggs, nauplii and metanauplii, and calyptopes on the $2^{\circ}$ longitude $\times 1^{\circ}$ latitude resolution grid from Perry et al. [2019; their supplementary material]. We included calyptope distribution within this dataset to better consider survival of spawned eggs until reaching free-swimming larvae, and to maximise spatial coverage of early-stages for model optimisation. Calyptopis stages are reached approximately 1 month after spawning [Thorpe et al., 2019], hence it is possible that during this time developing larvae may be advected beyond regions of good spawning habitat. However, given earlier developmental stages (nauplii and metanauplii) are associated with deep waters of relatively low current speeds, we expect calyptopes were sampled in the same grid cell as they were spawned.

This article is protected by copyright. All rights reserved. 
Each density dataset was log-transformed and normalised giving values scaled $0-1$. This reduced disparity between extremely high and low densities, allowing comparison between the three density maps. We combined the three datasets by taking the cellwise mean and again rescaling to $0-1$. The final composite density map consisted of 108 cells, encompassing approximately 1.4 million $\mathrm{km}^{2}$ (Fig. 1).

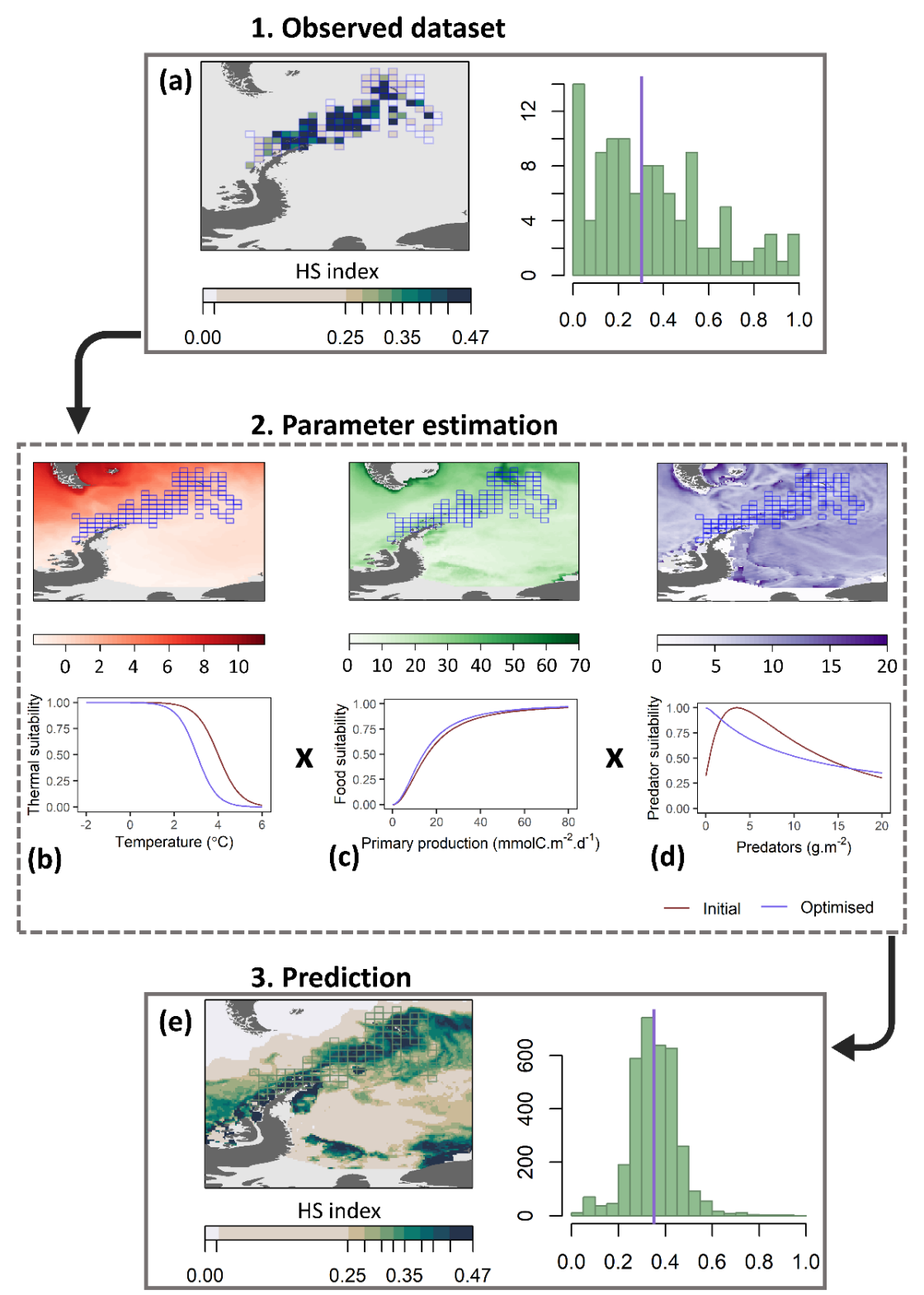

Fig. 1. Workflow for generating model predictions of spawning habitat. Panel (a) shows the observed composite density field (left) and the distribution of values. Panels (b), (c) and (d) show input variables

This article is protected by copyright. All rights reserved. 
(temperature, primary production and micronekton density respectively) as well as their respective suitability functions based on initial (red) and optimised (blue) parameters. Panel (e) shows predicted spawning habitat and distribution of values based on the product of the three optimised suitability functions. The colour in panels a and e represents percentile values of modelled spawning habitat (e), capped at the $90^{\text {th }}$ percentile; purple vertical lines in distributions represent the median.

\subsection{Modelling spawning habitat quality}

The composite density map was used to optimise a mechanistic model of spawning habitat quality driven by the underlying biophysical environment. To achieve this, we (1) defined the model structure and its component functions, (2) collated the underlying biophysical forcing variables and (3) optimised the model using maximum likelihood to estimate parameter values.

\subsubsection{Functions for modelling spawning habitat}

We assume at a given time a proportion [albeit variable; e.g. Reiss et al., 2020] of the adult female krill population is mature enough that under suitable thermal and food conditions they can produce eggs within 8 weeks [Quetin and Ross, 2001; Tarling, 2020; Thomas and Ikeda, 1987]. Spawned eggs sink to depths of $>500 \mathrm{~m}$ before hatching and returning to the surface as larvae [Hofmann et al., 1992]. During this descent/ascent cycle, we assume that egg and larval survival depends on the density of micronekton predators encountered.

Over the shelf, contact with the benthos is also conceptually recognized to reduce egg survival [Hofmann and Hüsrevoğlu, 2003; Thorpe et al., 2019]. However the largest compilation of observed nauplii and metanauplii densities gives values as high as 3805 no. $\mathrm{m}^{-2}$ in water shallower than 500m [Perry et al., 2019; and their supplementary material]. These data indicate egg survival may be nonzero in these shallower regions. Temperature, food availability and seasonal location of sea ice have also been highlighted as important determinants of calyptope survival following the descent/ascent cycle [Thorpe et al., 2019]. However, given our focus on survival only up to the calyptope stage, we considered inclusion of these variables to be beyond the scope of our current study.

We developed an index of spawning habitat quality by adapting methods in the 'Spatial Ecosystem and Population Dynamics Model' (SEAPODYM; see Lehodey et al. 2008 and Hernandez et al. 2014). This approach represents habitat quality as the product of suitability scores (scaled 0-1) for key biophysical variables affecting egg production and survival until free-

This article is protected by copyright. All rights reserved. 
swimming larval stages. Here we considered three key variables: (i) temperature; (ii) primary productivity (PP); and (iii) predator density. Spawning habitat quality $\left(\mathrm{H}_{s}\right)$ can thus be derived as:

Eq.1.

$$
H_{s}=f_{1}(T) \cdot f_{2}(P P) \cdot f_{3}(\text { Pred })
$$

where $f_{1}(T)$ is a sigmoid function (Eq.2.) representing metabolic tolerance of adult krill to variations in temperature, $f_{2}(P P)$ is a Holling type III functional response (Eq.3.) representing the suitability of the feeding environment (PP) for egg production, and $f_{3}($ Pred $)$ is a lognormal function (Eq.4.) representing survival of eggs and larvae under predation. Further detail on the selected functions, parameters and initial values is given in Text S1.

Eq.2.

$$
f_{1}(T)=\frac{1}{1+\exp ^{\lambda(T-\theta)}}
$$

Eq.3.

$$
f_{2}(P P)=\frac{P P^{2}}{\alpha+P P^{2}}
$$

Eq.4.

$$
f_{3}(\text { Pred })=\frac{1}{\text { Pred } \cdot e^{0.5 \cdot \sigma^{2}-\mu}} e^{-\frac{(\log (\text { Pred })-\mu)^{2}}{\sigma^{2}}}
$$

\subsubsection{Biophysical variables}

The three input variables required for parameterising the thermal, food and predator suitability functions were epipelagic depth-layer averaged temperature [Lehodey et al., 2015], surface primary production and modelled micronekton biomass consisting of six depth-related functional groups in the epipelagic through lower mesopelagic layers, including migrants and non-migrants [Lehodey et al., 2010; Lehodey et al., 2015]. We obtained all variables from forcing (temperature and primary production) and output (micronekton) fields of the SEAPODYM-LMTL 2.1.03 Global Ocean Low and Mid Trophic Levels Biomass Hindcast (https://resources.marine.copernicus.eu/?option=com_csw\&view=details\&product_id=GLOBAL_ REANALYSIS_BIO_001_033), at a $0.25^{\circ} \times 0.25^{\circ}$ spatial resolution and 1-week timestep from 07 Jan 1998 to 19 Dec 2018.

To consider recent conditions experienced by mature krill we computed an 8-week running mean of temperature and primary production. This reduced our year range to 1999-2017. We summed the six micronekton functional groups, creating a single biomass estimate between the surface 
and lower limit of the mesopelagic water column [Lehodey et al., 2015] or the seafloor (in waters $<1000 \mathrm{~m}$ ), encompassing the depth range of the krill descent/ascent cycle [Hofmann et al., 1992]. Then we created seasonal climatologies (Summer - Dec-Feb, Autumn - Mar-May, Winter - JunAug, Spring - Sep-Nov) of all three variables. We spatially aggregated these to $2^{\circ} \times 1^{\circ}$ cells to match observations. Outliers $(n=1)$ were removed following Chauvenet's criterion [Chauvenet, 1863].

\subsubsection{Parameter estimation}

To estimate the five parameters required for model configuration (Table 1) we used the $R$ package stats4 (optimiser method "L-BFGS-B"; $R$ Core Team [2020]), using R-3.6.3 [R Core Team, 2020]. The optimiser finds the minimum of the negative log-likelihood, after which an approximate parameter covariance matrix is obtained through inverting the Hessian matrix. Modelled spawning habitat (Eq.1.) was evaluated cellwise against our composite density map. Since peak spawning occurs over Dec-Feb [Quetin et al., 1994] we optimised parameters using austral summer biophysical climatologies.

Table 1: Definitions of parameters for the three suitability functions used in the calculation of spawning habitat quality. Initial values are given alongside the optimised values and their standard errors. See Text $\mathrm{S} 1$ for background of initial parameter values.

\begin{tabular}{|c|c|c|c|c|}
\hline Parameter & Description & $\begin{array}{l}\text { Initial } \\
\text { values }\end{array}$ & $\begin{array}{l}\text { Optimised } \\
\text { values }\end{array}$ & Std. Error \\
\hline$f_{1}(T)$ & Sigmoid curve & & & \\
\hline$\Theta$ & Threshold value & 4 & 3.03 & 1.19 \\
\hline$\lambda$ & Slope coefficient & 2 & 2.20 & 3.90 \\
\hline$f_{2}(P P)$ & $\begin{array}{l}\text { Holling type III } \text { functional } \\
\text { response }\end{array}$ & & & \\
\hline$\alpha$ & Encounter rate (slope coefficient) & 250 & 196.30 & 380.96 \\
\hline$f_{3}($ Pred $)$ & Log-normal curve & & & \\
\hline$\mu$ & Mean & 2.5 & 4.59 & 18.27 \\
\hline$\sigma$ & Standard deviation & 1 & 2.16 & 5.64 \\
\hline
\end{tabular}

\subsubsection{Spatio-temporal model projections of spawning habitat quality}

Finally, we computed circumpolar projections using optimised parameter estimates with reaggregated input variables at climatological and annual monthly, and weekly temporal scales. We also compiled annual January spawning habitat averages for the AP CCAMLR subarea 48.1

This article is protected by copyright. All rights reserved. 
(Table S2) and compared this interannual timeseries against following-year observed densities of krill [see Text S2 for methods, Atkinson et al., 2017] for the northern AP. Krill densities were collected by the US Antarctic Marine Living Resources Programme (AMLR), representing the longest running and most spatially consistent dataset within our study period.

This article is protected by copyright. All rights reserved. 


\section{Results and Discussion}

\subsection{Observed spawning habitat and optimisation results}

From the sampling coverage we derived a regional composite density map that extended northwards and eastwards from the AP, encompassing the Scotia Arc and SG (Fig. 1a). The optimisation procedure indicated thermal suitability was more constrained than expected under initial values, with optimal temperatures to $\sim 1.5^{\circ} \mathrm{C}$ decreasing rapidly towards zero at $\sim 4^{\circ} \mathrm{C}$ (Fig. 1b). This is consistent with studies showing temperature preferences between -1.5 and $1.5^{\circ} \mathrm{C}$ [Cuzin-Roudy et al., 2014; Perry et al., 2019]. Furthermore, even if warmer waters could support egg production, hatchability and early larval development are impaired at temperatures greater than $3^{\circ} \mathrm{C}$ [Perry et al., 2020]. The optimised food suitability function (Fig. 1C) approached saturation when primary production exceeded values of $40 \mathrm{mmol} \mathrm{C} \cdot \mathrm{m}^{-2} \cdot \mathrm{d}^{-1}$, spatially congruent with highly productive areas (both for phytoplankton and krill) around the AP and SG [Korb et al., 2005; Marrari et al., 2008; Siegel and Watkins, 2016]. Parameter estimates for predator suitability were also more constrained than initial parameters (Fig. 1d). Optimal predator densities were $\sim 1$ g. $\mathrm{m}^{-2}$ (compared to the initial $4 \mathrm{~g} \cdot \mathrm{m}^{-2}$ ) and decreased steeply thereafter, effectively halving at 10 $\mathrm{g} \cdot \mathrm{m}^{-2}$. This seems reasonable given that optimal spawning habitat quality should manifest as high larval survival in regions of lowest predator biomass. Spatially, our predator suitability function shows high predation survival in shelf and shelf slope waters where krill eggs and young larvae are found in high densities [Perry et al., 2019].

Our optimised regional spawning habitat quality map (Fig. 1e) showed similar spatial patterning to the observed habitat (Fig. 1a), with a mean difference of 0.1 and root mean squared error of 0.25 (Fig. S2) . In both cases, areas of highest spawning habitat quality are located around the $A P$, the vicinity of $S G$, and a narrow band between these two areas particularly around the South Orkney Islands. Overall, modelled spawning habitat showed a more constrained distribution, displaying a lower frequency of high-value cells than observed. However, both had similar median values ( 0.35 vs 0.30 for modelled and observed spawning habitat, respectively), and their spatial congruency was supported by a generalised least squares model incorporating Gaussian spatial autocorrelation, which indicated significant correlation between the two (coefficient: 0.71; $p=0.005$; residual SE: 0.36 ).

\subsection{Circumpolar patterns in summer krill spawning habitat}


Using our optimised parameter estimates, we generalised the model from our regional prediction to seasonal circumpolar estimates of spawning habitat quality (Fig. 2a). As expected, habitat quality peaked in austral summer (global median of 0.28 for waters colder than $4^{\circ} \mathrm{C}$; the northern limit of potential krill spawning habitat from Fig. 1b). The highest quality habitat was located in coastal waters around Antarctica, and oceanic waters in the southwest Atlantic stretching northeastwards from the AP beyond SG (locations in Fig. S4). Krill are unevenly distributed across their range [Atkinson et al., 2008] and the Atlantic sector of the Southern Ocean accounts for more than $50 \%$ of krill biomass [Siegel and Watkins, 2016]. The prevalence of good-quality modelled spawning habitat is congruent with this, indicating the region can support high larval production. However, while high-quality spawning habitat exists around SG, our understanding holds that this population is not self-sustaining and depends on imported recruits [Tarling et al., 2007]. Here, good spawning conditions might not translate into post-larval biomass because later conditions are unsuitable for recruitment, or recruits are exported from the population [Tarling et al., 2007].

Along the remainder of the Antarctic coast, our model predicted high-quality spawning habitat in two largely continuous bands, one extending east of the Weddell Sea and another stretching from the Ross Sea to the AP. High densities of larval or post-larval krill are documented across much of this high-quality habitat [Siegel and Watkins, 2016] but are notably absent from the Amundsen Sea. Previous modelling has also predicted a high probability of post-larval krill presence within this region [Cuzin-Roudy et al., 2014] and the species' observed absence may be an artifact of low sampling effort [Cuzin-Roudy et al., 2014]. Around much of the remaining Antarctic coastline, spawning habitat tended to be patchy and hug the continent, similar to previous predictions [Cuzin-Roudy et al., 2014].

Much of the oceanic spawning habitat was of relatively high quality during summer (Fig. 2a), suggesting that these environments could support successful larval production. The extent to which this manifests in recruitment is interesting given that $87 \%$ of the krill stock occurs in deep waters, albeit at low densities [Atkinson et al., 2008]. However, while potentially favourable oceanic spawning habitat is extensive, much of it lies north of the core distribution of krill [Fig. 2a, but see also Cuzin-Roudy et al., 2014]. As with South Georgia, this is likely a result of conditions unfavourable for recruitment [e.g. absence of winter sea-ice habitat; Melbourne-Thomas et al., 2016; Thorpe et al., 2019]. Ultimately, the realised quality of spawning habitat would depend on conditions suitable for survival across all of krill's key developmental stages.

This article is protected by copyright. All rights reserved. 
(a) Winter

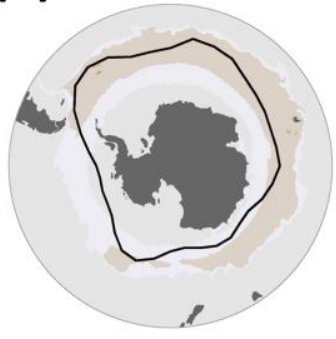

Spring

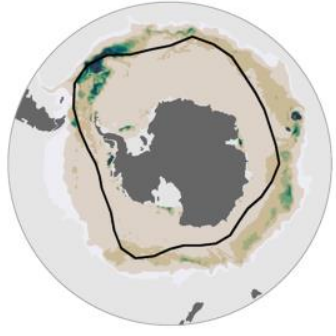

Summer

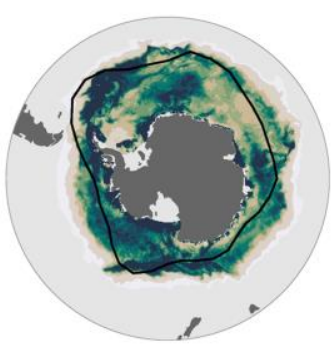

Autumn
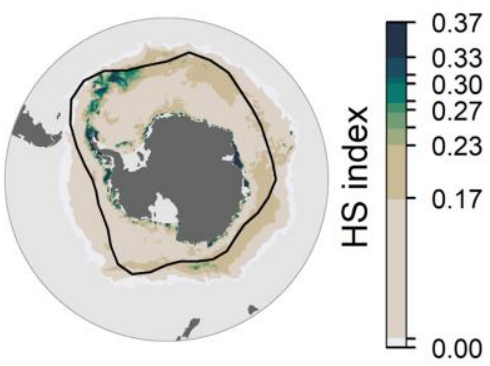

(b)

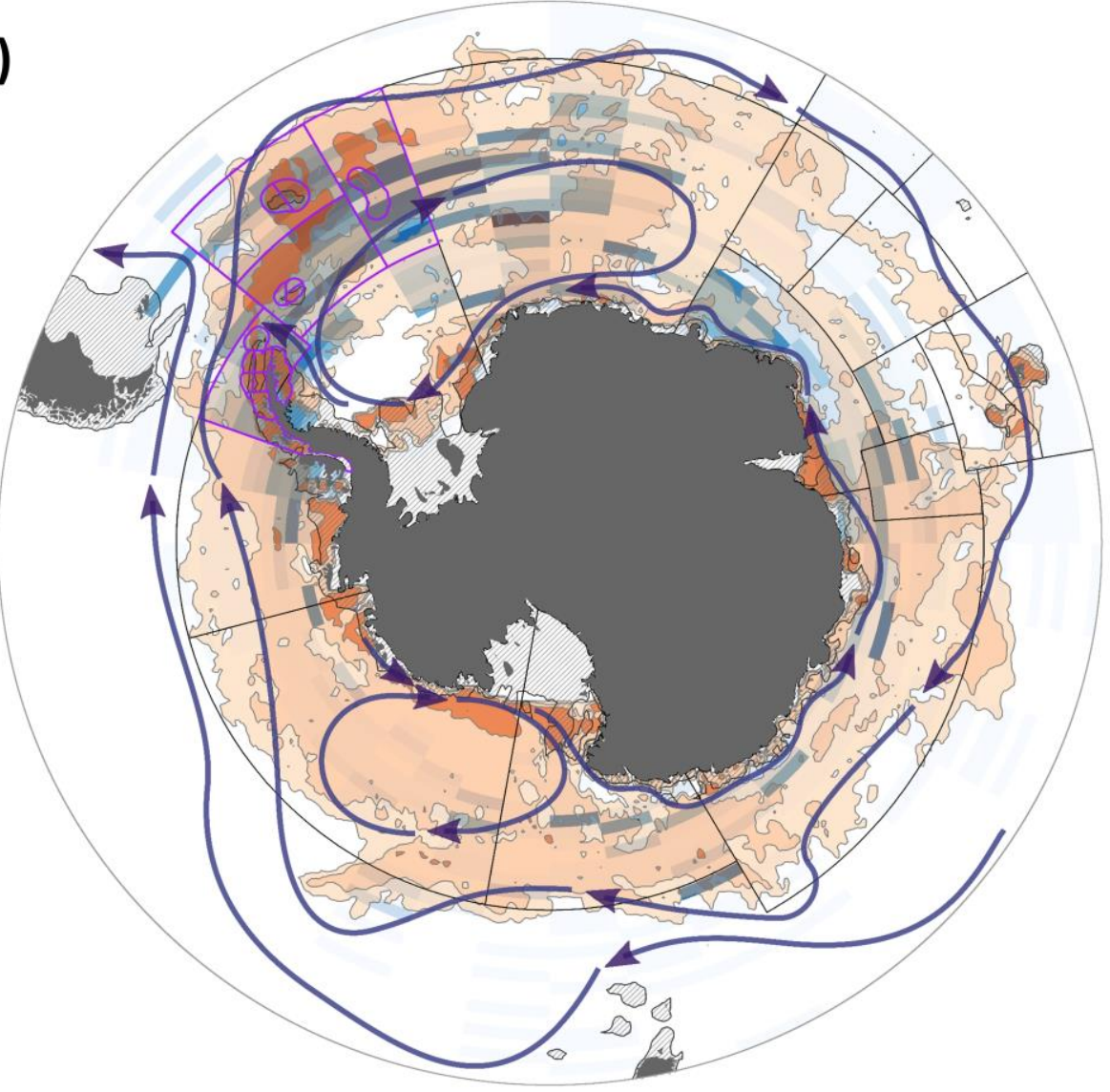

Duration of high quality spawning habitat

\section{1-3 weeks \\ 4-11 weeks \\ $12+$ weeks}

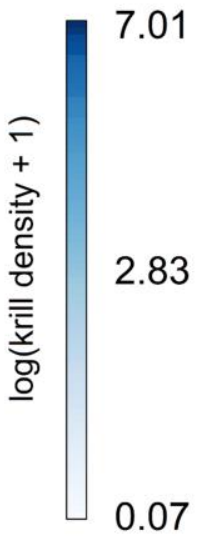

Fig. 2. Distribution of seasonal circumpolar spawning habitat (a) and mean annual duration over which spawning habitat quality is higher than the summer $80^{\text {th }}$ percentile (b). For panel (a) colour scale breaks are given by summer percentile values and capped at the $90^{\text {th }}$ percentile, while greyed-out regions represent values approximating zero $(<0.001)$. The northern limit to the distribution of Antarctic krill is given by the black line in panel (a), and krill density is denoted by the blue colour scale in panel (b) [data obtained through KRILLBASE; Atkinson et al., 2017]; see Text S2 for methods. Black and purple polygons in panel (b) give the CCAMLR statistical subareas and small-scale management units (SSMUs) respectively. 
Dominant ocean currents are denoted by the blue arrows (adapted from Post et al. [2014]), and hatched regions denote $500 \mathrm{~m}$ isobath (GEBCO_08; www.gebco.net).

\subsection{Seasonal and interannual variability in krill spawning habitat}

Modelled spawning habitat quality was considerably lower outside of summer (global medians: $<0.01,0.13$ and 0.15 for winter, spring, and autumn, respectively) coinciding with the loss of most high-quality coastal and oceanic spawning habitat areas and seasonal reductions in primary productivity. However, some areas maintained persistently high quality from spring through autumn (mainly November to March; Fig. S5). To spatially represent these persistent high-quality habitats (Fig. 2b), we calculated the mean number of weeks per year that modelled spawning habitat quality remained above the $80^{\text {th }}$ percentile of all summer habitat within waters colder than $4^{\circ} \mathrm{C}$. This shows areas supporting the highest summer spawning habitat quality, particularly those focal areas along the continent, and extending north-eastwards from the AP, also tended to maintain high values for longer (i.e., $\geq$ three months). Mature female krill can spawn multiple times a season, provided they remain exposed to suitable feeding conditions [Kawaguchi, 2016]. Regions maintaining persistently high-quality spawning habitat could maximise seasonal production by allowing multiple spawning cycles; thereby contributing disproportionately to global krill production.

Krill biomass is highly variable across years, typically following cyclical patterns driven by the underlying environment [Conroy et al., 2020] and/or intraspecific competition [Ryabov et al., 2017]. Extending our approach, we considered interannual variability by computing a normalised anomaly index for January mean modelled spawning habitat quality within the AP region (CCAMLR Subarea 48.1; Table S2). Our timeseries indicated a cyclical pattern in high-quality habitat of 4-5 years, interspersed by years of relatively poor quality (Fig. 3). These patterns were correlated with following-year krill densities sampled at the northern AP (generalised least squares with order-1 temporal autocorrelation: coefficient: $1.05 ; p=0.004$; residual SE: 0.38). Particularly notable were peaks and troughs of spawning habitat quality over 2002 and 2006, as

well as 2003-2005 and 2008-2010, followed by years of high and low krill densities respectively (Fig. 2b). Also notable was a series of below-average years between 2013 and 2016. Post-larval densities of krill in the northern AP are not available over this period, but winter surveys in the same region found these years to have low larval production [Reiss et al., 2020].

This article is protected by copyright. All rights reserved. 


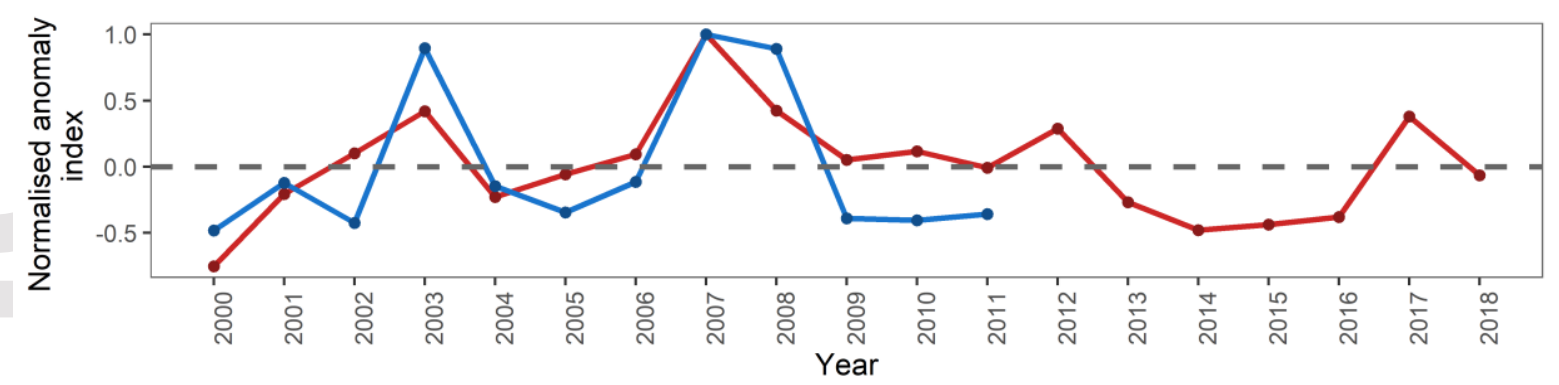

Fig. 3. Interannual variability of modelled krill spawning habitat quality and subsequent observed post-larval krill densities for the AP. Modelled spawning habitat (red) is given as a 1-year lagged January annual mean along the west AP (CCAMLR statistical Subarea 48.1) co-plotted with the observed annual mean of logtransformed krill density (blue) for the northern AP [Atkinson et al., 2017]. Both time series are represented as anomalies scaled between -1 and 1 . See Text S2 for methods.

\subsection{Spatial management implications and further work}

Our approach identified approximately 2.05 million $\mathrm{km}^{2}$ of optimal spawning habitat (areas maintaining habitat quality above the summer $80^{\text {th }}$ percentile for at least three months; Fig. $2 \mathrm{~b}$ ), spanning much of coastal Antarctica and the oceanic southwest Atlantic. Of this, $\sim 48 \%$ was represented by CCAMLR Subareas 48.1-48.5 spanning the western AP to the eastern Weddell Sea. A further $\sim 35 \%$ was within subareas 88.1-3, extending between the Ross and Bellinghausen Seas (Table S2). The remaining half of the Southern Ocean (Subareas 48.6 and 58.4.1-58.5.2) accounted only $26 \%$ of the calculated optimal spawning habitat. In the key southwest Atlantic sector Subareas, designated CCAMLR small-scale management units (SSMUs) contained 76\% of optimal spawning habitat within the AP Subarea (48.1) and 35\% for SG (48.3). However SSMUs contained only 6-7\% of optimal habitat within each of the South Orkney (48.2) and South Sandwich (48.4) Subareas, suggesting reliance on external sources of larval production. If we exclude shelf areas ( $<500 \mathrm{~m}$, Table S2, hatched area Fig. 2b) under the notion of impaired egg survival, the importance of most SSMUs is reduced; and particularly the east and west AP, and South Orkneys. However, high-quality habitat within Bransfield Strait, a key krill area [Santa Cruz et al., 2018], remains relatively well represented even when excluding shallow water. This emphasizes the role of the AP as a source for the downstream population. Reliance on upstream import raises implications for small-scale spatial management of the krill fishery, as a key purpose of the SSMUs is to spread catch thereby reducing impacts on dependent ecosystems [Constable, 2011; Hill et al., 2016].

This article is protected by copyright. All rights reserved. 
If the Peninsula region acts as a source, spatial management of the fishery harvest within the 48.1 SSMUs will be of prime importance. Apart from managing localised competition between cooccurring fisheries and marine predators within SSMUs [e.g. Plagányi and Butterworth, 2012; Watters et al., 2020; Weinstein et al., 2017], these results lend support to the idea of concentrated extraction around the AP having downstream consequences for the regional krill population.

We generated circumpolar projections of spawning habitat based on a regional data source, which itself was identified as of global importance by our model. However, given krill's heterogenous circumpolar distribution, spawning habitat requirements may differ regionally. Our approach could benefit from optimisation against equivalent datasets from other regions, allowing us to better assess spatial variability. Finally, while characterising habitat supporting larval production is important for defining regions that act as sources of the krill population, it provides only a partial picture for a species with a complex life history (for example, we have omitted several variables important for successful recruitment following descent/ascent [e.g. Piñones and Fedorov, 2016; Thorpe et al., 2019]). However, our findings will feed into a more complete model encompassing the full life history of krill and associated requirements for key stages of development [e.g. Melbourne-Thomas et al., 2016; Piñones and Fedorov, 2016; Thorpe et al., 2019], as well as transport processes acting to redistribute krill throughout its life [Fiechter et al., 2020; Hofmann and Murphy, 2004; Thorpe et al., 2007]. This will be achieved through adapting an existing and proven framework of spatially dynamic ecosystem-driven population models [Lehodey et al., 2008]. Such modelling will help better understand circumpolar recruitment and connectivity within the krill population; ultimately informing sustainable management of the expanding fishery under rapid environmental change [Flores et al., 2012; Meyer et al., 2020].

\section{Acknowledgments}

This study received support from the European H2020 International Cooperation project MESOPP No 692173 (Mesopelagic Southern Ocean Prey and Predators, www.mesopp.eu/). D.B.G. was funded through a Tasmania Graduate Research Scholarship. S.B. was supported by the Australian Research Council under DECRA award DE180100828. We thank Inna Senina and Olivier Titaud for providing initial scripts and technical assistance. Andrew Constable and So Kawaguchi provided helpful discussions during conceptualisation. We also thank two anonymous reviewers who provided useful comments that improved our manuscript. Model data are available through the IMAS data portal (https://doi.org/10.25959/XXGM-N693).

This article is protected by copyright. All rights reserved. 


\section{References}

Atkinson, A., R. S. Shreeve, A. G. Hirst, P. Rothery, G. A. Tarling, D. W. Pond, R. E. Korb, E. J. Murphy, and J. L. Watkins (2006), Natural growth rates in Antarctic krill (Euphausia superba): II. Predictive models based on food, temperature, body length, sex, and maturity stage, Limnology and Oceanography, 51(2), 973-987, doi: 10.4319/lo.2006.51.2.0973.

Atkinson, A., V. Siegel, E. Pakhomov, P. Rothery, V. Loeb, R. Ross, L. Quetin, K. Schmidt, P. Fretwell, and E. Murphy (2008), Oceanic circumpolar habitats of Antarctic krill, Marine Ecology Progress Series, 362, 1-23, doi: 10.3354/meps07498.

Atkinson, A., et al. (2019), Krill (Euphausia superba) distribution contracts southward during rapid regional warming, Nature Climate Change, 9(2), 142-147, doi: 10.1038/s41558-0180370-z.

Atkinson, A., et al. (2017), KRILLBASE: a circumpolar database of Antarctic krill and salp numerical densities, 1926-2016, Earth System Science Data, 9(1), 193-210, doi: 10.5194/essd-9-193-2017.

Ballerini, T., E. E. Hofmann, D. G. Ainley, K. Daly, M. Marrari, C. A. Ribic, W. O. Smith, and J. $\mathrm{H}$. Steele (2014), Productivity and linkages of the food web of the southern region of the western Antarctic Peninsula continental shelf, Progress in Oceanography, 122, 10-29, doi: 10.1016/j.pocean.2013.11.007.

Chauvenet, W. (1863), A manual of spherical and practical astronomy, J. B. Lippincott \& Co., Philadelphia, PA.

Conroy, J. A., C. S. Reiss, M. R. Gleiber, and D. K. Steinberg (2020), Linking Antarctic krill larval supply and recruitment along the Antarctic Peninsula, Integrative and Comparative Biology, doi: 10.1093/icb/icaa111.

Constable, A. J. (2011), Lessons from CCAMLR on the implementation of the ecosystem approach to managing fisheries, Fish and Fisheries, 12(2), 138-151, doi: 10.1111/j.14672979.2011.00410.x.

Constable, A. J., and S. Kawaguchi (2018), Modelling growth and reproduction of Antarctic krill, Euphausia superba, based on temperature, food and resource allocation amongst life history functions, ICES Journal of Marine Science, 75(2), 738-750, doi:

10.1093/icesjms/fsx190.

Cuzin-Roudy, J., J. Irisson, F. Penot, S. Kawaguchi, and C. Vallet (2014), Southern Ocean Euphausiids, in Biogeographic Atlas of the Southern Ocean, edited by C. De Broyer, et al., pp. 309-320, Scientific Committee on Antarctic Research, Cambridge. 
Fach, B. A., E. E. Hofmann, and E. J. Murphy (2006), Transport of Antarctic krill (Euphausia superba) across the Scotia Sea. Part II: Krill growth and survival, Deep Sea Research Part I. Oceanographic Research Papers, 53(6), 1011-1043, doi: 10.1016/j.dsr.2006.03.007.

Fiechter, J., J. A. Santora, F. Chavez, D. Northcott, and M. Messié (2020), Krill Hotspot Formation and Phenology in the California Current Ecosystem, Geophysical Research Letters, 47(13), doi: 10.1029/2020gl088039.

Flores, H., et al. (2012), Impact of climate change on Antarctic krill, Marine Ecology Progress Series, 458, 1-19, doi: 10.3354/meps09831.

Hernandez, O., P. Lehodey, I. Senina, V. Echevin, P. Ayón, A. Bertrand, and P. Gaspar (2014), Understanding mechanisms that control fish spawning and larval recruitment: Parameter optimization of an Eulerian model (SEAPODYM-SP) with Peruvian anchovy and sardine eggs and larvae data, 123, 105-122, doi: 10.1016/j.pocean.2014.03.001.

Hill, S. L., A. Atkinson, C. Darby, S. Fielding, B. A. Krafft, O. R. Godø, G. Skaret, P. N. Trathan, and J. L. Watkins (2016), Is current management of the Antarctic krill fishery in the Atlantic sector of the Southern Ocean precautionary?, CCAMLR Science, 23, 31-51.

Hofmann, E. E., and Y. S. Hüsrevoğlu (2003), A circumpolar modeling study of habitat control of Antarctic krill (Euphausia superba) reproductive success, Deep Sea Research Part II: Topical Studies in Oceanography, 50(22-26), 3121-3142, doi: 10.1016/j.dsr2.2003.07.012.

Hofmann, E. E., and E. J. Murphy (2004), Advection, krill, and Antarctic marine ecosystems, Antarctic Science, 16(4), 487-499, doi: 10.1017/s0954102004002275.

Hofmann, E. E., J. E. Capella, R. M. Ross, and L. B. Quetin (1992), Models of the early life history of Euphausia superba-Part I. Time and temperature dependence during the descent-ascent cycle, Deep Sea Research Part I. Oceanographic Research Papers, 39(7), 1177-1200, doi: 10.1016/0198-0149(92)90063-Y.

Kawaguchi, S. (2016), Reproduction and larval development in Antarctic krill (Euphausia superba), in Biology and ecology of Antarctic krill, edited by V. Siegel, pp. 225-246, Springer, Basel, Switzerland.

Korb, R. E., M. J. Whitehouse, S. E. Thorpe, and M. Gordon (2005), Primary production across the Scotia Sea in relation to the physico-chemical environment, Journal of Marine Systems, 57(3), 231-249, doi: 10.1016/j.jmarsys.2005.04.009.

Lehodey, P., I. Senina, and R. Murtugudde (2008), A spatial ecosystem and populations dynamics model (SEAPODYM)-Modeling of tuna and tuna-like populations, Progress in Oceanography, 78(4), 304-318, doi: 10.1016/j.pocean.2008.06.004.

This article is protected by copyright. All rights reserved. 
Lehodey, P., R. Murtugudde, and I. Senina (2010), Bridging the gap from ocean models to population dynamics of large marine predators: a model of mid-trophic functional groups, Progress in Oceanography, 84(1-2), 69-84, doi: 10.1016/j.pocean.2009.09.008.

Lehodey, P., A. Conchon, I. Senina, R. Domokos, B. Calmettes, J. Jouanno, O. Hernandez, and R. Kloser (2015), Optimization of a micronekton model with acoustic data, ICES Journal of Marine Science, 72(5), 1399-1412, doi: 10.1093/icesjms/fsu233.

Marr, J. W. S. (1962), The natural history and geography of the Antarctic krill (Euphausia superba Dana), Discovery Rep., 32, 33-464.

Marrari, M., K. L. Daly, and C. Hu (2008), Spatial and temporal variability of SeaWiFS chlorophyll a distributions west of the Antarctic Peninsula: Implications for krill production, Deep Sea Research Part II: Topical Studies in Oceanography, 55(3-4), 377-392, doi: 10.1016/j.dsr2.2007.11.011.

Melbourne-Thomas, J., S. P. Corney, R. Trebilco, K. M. Meiners, R. P. Stevens, S. Kawaguchi, M. D. Sumner, and A. J. Constable (2016), Under ice habitats for Antarctic krill larvae: Could less mean more under climate warming?, Geophysical Research Letters, 43(19), 10322-10327, doi: 10.1002/2016gl070846.

Meyer, B., et al. (2020), Successful ecosystem-based management of Antarctic krill should address uncertainties in krill recruitment, behaviour and ecological adaptation, Communications Earth \& Environment, 1(1), doi: 10.1038/s43247-020-00026-1.

Mori, M., S. P. Corney, J. Melbourne-Thomas, A. Klocker, S. Kawaguchi, A. Constable, and M. Sumner (2019), Modelling dispersal of juvenile krill released from the Antarctic ice edge: Ecosystem implications of ocean movement, Journal of Marine Systems, 189, 50-61, doi: 10.1016/j.jmarsys.2018.09.005.

Murphy, E. J., S. E. Thorpe, G. A. Tarling, J. L. Watkins, S. Fielding, and P. Underwood (2017), Restricted regions of enhanced growth of Antarctic krill in the circumpolar Southern Ocean, Scientific Reports, 7(1), 6963, doi: 10.1038/s41598-017-07205-9.

Nicol, S., J. Foster, and S. Kawaguchi (2012), The fishery for Antarctic krill - recent developments, Fish and Fisheries, 13(1), 30-40, doi: 10.1111/j.1467-2979.2011.00406.x.

Perry, F. A., A. Atkinson, S. F. Sailley, G. A. Tarling, S. L. Hill, C. H. Lucas, and D. J. Mayor (2019), Habitat partitioning in Antarctic krill: Spawning hotspots and nursery areas, PLoS One, 14(7), e0219325, doi: 10.1371/journal.pone.0219325.

Perry, F. A., S. Kawaguchi, A. Atkinson, S. F. Sailley, G. A. Tarling, D. J. Mayor, C. H. Lucas, R. King, and A. Cooper (2020), Temperature-induced hatch failure and nauplii malformation in Antarctic krill, Frontiers in Marine Science, 7, doi: 10.3389/fmars.2020.00501.

This article is protected by copyright. All rights reserved. 
Pinheiro, J., D. Bates, S. DebRoy, and D. Sarkar (2020), nIme: Linear and Nonlinear Mixed Effects Models, https://CRAN.R-project.org/package=n/me.

Piñones, A., and A. V. Fedorov (2016), Projected changes of Antarctic krill habitat by the end of the 21st century, Geophysical Research Letters, 43(16), 8580-8589, doi: 10.1002/2016GL069656.

Plagányi, É. E., and D. S. Butterworth (2012), The Scotia Sea krill fishery and its possible impacts on dependent predators: modeling localized depletion of prey, 22(3), 748-761, doi: 10.1890/11-0441.1.

Post, A. L., et al. (2014), Chapter 4. Environmental Setting, in Biogeographic Atlas of the Southern Ocean, edited by K. P. De Broyer C., Griffths H.J., Raymond B., Udekem d'Acoz C. d', Van de Putte A.P., Danis B., David B., Grant S., Gutt J., Held C., Hosie G., Huettmann and P. A. F., Ropert-Coudert Y, pp. 46-64, Scientifc Committee on Antarctic Research, Cambridge.

Quetin, L. B., and R. M. Ross (2001), Environmental variability and its impact on the reproductive cycle of Antarctic krill, American Zoologist, 41(1), 74-89, doi: 10.1093/icb/41.1.74.

Quetin, L. B., R. Ross, and A. Clarke (1994), Krill energetics: seasonal and environmental aspects of the physiology of Euphausia superba, in Southern Ocean ecology: the BIOMASS perspective, edited, Cambridge University Press, Cambridge.

R Core Team (2020), R: A language and environment for statistical computing, R Foundation for Statistical Computing, Vienna, Austria.

Ratnarajah, L., and Andrew (2016), Nutrient cycling: are Antarctic krill a previously overlooked source in the marine iron cycle?, Current Biology, 26(19), R884-R887, doi: 10.1016/j.cub.2016.08.044.

Reiss, C. S., J. T. Hinke, and G. M. Watters (2020), Demographic and maturity patterns of Antarctic krill (Euphausia superba) in an overwintering hotspot, Polar Biology, doi: 10.1007/s00300-020-02704-4.

Ryabov, A. B., A. M. De Roos, B. Meyer, S. Kawaguchi, and B. Blasius (2017), Competitioninduced starvation drives large-scale population cycles in Antarctic krill, Nature Ecology \& Evolution, 1, 0177, doi: 10.1038/s41559-017-0177.

Santa Cruz, F., B. Ernst, J. A. Arata, and C. Parada (2018), Spatial and temporal dynamics of the Antarctic krill fishery in fishing hotspots in the Bransfield Strait and South Shetland Islands, Fisheries Research, 208, 157-166, doi: 10.1016/j.fishres.2018.07.020. 
Saunders, R. A., S. L. Hill, G. A. Tarling, and E. J. Murphy (2019), Myctophid fish (family Myctophidae) are central consumers in the food web of the Scotia Sea (Southern Ocean), Frontiers in Marine Science, 6(530), doi: 10.3389/fmars.2019.00530.

Senina, I. N., P. Lehodey, J. Hampton, and J. Sibert (2019), Quantitative modeling of the spatial dynamics of South Pacific and Atlantic albacore tuna populations, Deep Sea Research Part II: Topical Studies in Oceanography, 175, doi: 10.1016/j.dsr1012.2019.104667, doi: 10.1016/j.dsr2.2019.104667.

Siegel, V., and J. L. Watkins (2016), Distribution biomass and demography of Antarctic krill Euphausia superba, in Biology and ecology of Antarctic krill, edited by V. Siegel, pp. 21 100, Springer, Basel, Switzerland.

Siegel, V., R. M. Ross, and L. B. Quetin (2003), Krill (Euphausia superba) recruitment indices from the western Antarctic Peninsula: are they representative of larger regions?, 26(10), 672-679, doi: 10.1007/s00300-003-0537-5.

Tarling, G. A. (2020), Routine metabolism of Antarctic krill (Euphausia superba) in South Georgia waters: absence of metabolic compensation at its range edge, Marine Biology, 167(8), doi: 10.1007/s00227-020-03714-w.

Tarling, G. A., J. Cuzin-Roudy, S. E. Thorpe, R. S. Shreeve, P. Ward, and E. J. Murphy (2007), Recruitment of Antarctic krill Euphausia superba in the South Georgia region: adult fecundity and the fate of larvae, 331, 161-179, doi: 10.3354/meps331161.

Thomas, P. G., and T. Ikeda (1987), Sexual regression, shrinkage, re-maturation and growth of spent female Euphausia superba in the laboratory, Marine Biology, 95(3), 357-363, doi: 10.1007/bf00409565.

Thorpe, S. E., E. J. Murphy, and J. L. Watkins (2007), Circumpolar connections between Antarctic krill (Euphausia superba Dana) populations: Investigating the roles of ocean and sea ice transport, 54(5), 792-810, doi: 10.1016/j.dsr.2007.01.008.

Thorpe, S. E., G. A. Tarling, and E. J. Murphy (2019), Circumpolar patterns in Antarctic krill larval recruitment: an environmentally driven model, Marine Ecology Progress Series, 613, 77-96, doi: 10.3354/meps 12887 .

Trebilco, R., J. Melbourne-Thomas, M. Sumner, S. Wotherspoon, and A. Constable (2019), Assessing status and trends of open ocean habitats: A regionally resolved approach and Southern Ocean application, Ecological Indicators, 107, 105616, doi:

10.1016/j.ecolind.2019.105616.

This article is protected by copyright. All rights reserved. 
Veytia, D., S. Corney, K. M. Meiners, S. Kawaguchi, E. J. Murphy, and S. Bestley (2020), Circumpolar projections of Antarctic krill growth potential, Nature Climate Change, 10(6), 568-575, doi: 10.1038/s41558-020-0758-4.

Watters, G. M., J. T. Hinke, and C. S. Reiss (2020), Long-term observations from Antarctica demonstrate that mismatched scales of fisheries management and predator-prey interaction lead to erroneous conclusions about precaution, Scientific Reports, 10(1), doi: 10.1038/s41598-020-59223-9.

Weinstein, B. G., M. Double, N. Gales, D. W. Johnston, and A. S. Friedlaender (2017), Identifying overlap between humpback whale foraging grounds and the Antarctic krill fishery, Biological Conservation, 210, 184-191, doi: 10.1016/j.biocon.2017.04.014.

Yang, G., A. Atkinson, S. L. Hill, L. Guglielmo, A. Granata, and C. Li (2020), Changing circumpolar distributions and isoscapes of Antarctic krill: Indo-Pacific habitat refuges counter long-term degradation of the Atlantic sector, Limnology and Oceanography, doi: 10.1002/Ino.11603.

This article is protected by copyright. All rights reserved. 